\title{
The IAU and Contemporary Global Challenges: A Latin American Point of View
}

\author{
Juan Ramón de la Fuente
}

In today's world, in which the problems that affect us all are interconnected, global problems and global issues require global solutions. Pandemics, climate change, the growing waves of intolerance, inequality and migration are but some examples of the challenges that require a joint response. In a context where global, multiple stakeholders are needed to formulate efficient solutions to these global problems, universities must play a more active role. To this end, the IAU, the only truly global association of universities, offers a unique and important platform to foster that role.

There is a positive balance on the impact generated by international and multistakeholder cooperation. Multilateralism is a form of international cooperation that led to the formation of the UN. I believe globalism and multilateralism are far better approaches to addressing global problems than nationalism. The current context we live in offers a great opportunity for the International Association of Universities because its mission and scope are suited to this context. There is no equivalence to it in the academic world. But it is precisely in this sense that work must be done to implement innovative approaches, new activities, to think out of the box, to network, to attract and consolidate a diverse community, to allow us to move forward as an academic family in its pluralistic nature.

The idea of an isolated university or a higher education institution or even a national system, devoting its energy, efforts, talent and resources just to satisfy its own interests and curiosity is no longer viable. Universities do have a local mission; however, its regional and international interactions will strengthen it. For this reason, it is essential that universities engage with each other and with diverse, multiple stakeholders in order to overcome the countless local and global challenges. They need to work together, not only across regions but across continents. If not, given the times in which we are living, it will be difficult to maintain a wide perspective,

J. R. de la Fuente $(\bowtie)$

Permanent Representative of Mexico to the United Nations, New York, NY, USA

e-mail: jrfuente1@gmail.com

(C) The Author(s) 2021

H. van't Land et al. (eds.), The Promise of Higher Education,

https://doi.org/10.1007/978-3-030-67245-4_4 
justify its profound reason d'être to foster its leadership role and receive the social recognition needed to effectively play such a role.

The specific socio-economic and cultural context in which universities operate has always been crucial for defining the university role. The context that prevails in society has always been relevant when understanding the role of universities. Currently, we are experiencing low levels of confidence and high levels of anxiety in many regions of the world. Loss of confidence in traditional institutions that have not been up to the expectations of the young produces a feeling of frustration in both students and faculty. While in the past, the mere fact of entering higher education basically ensured that the expectations of the majority were met, students today are not satisfied with being admitted to a university and obtaining a degree. There needs to be something else in the process, an additional social value. A more robust offer is needed. This perception, if correct, bids us to reflect on the role that universities must play today, to become a source of solutions and not of frustration. That is one of the challenges higher education faces.

A stepping-stone in such a direction lies in recognising that universities need to engage in cooperation and partnerships among each other and with other stakeholders. To build their foundations as part of the solution, universities must not only innovate curricula, they must also partner more effectively with the private sector, civil society, government agencies, multilateral institutions, as well as other allies at the local, regional and global levels. They need to succeed to counteract the growing spiral of frustration and to regain and/or strengthen moral authority.

Recognising that partners are needed, and that those partnerships need to be innovative and effective is something that must be fostered. There are examples of institutions that have been able to achieve this, albeit only to some extent. We must look into them in depth and take advantage of their experience. These are the kinds of projects that IAU may emphasise more strongly and share with its membership and beyond.

In addition to multi-stakeholder partnerships, there are also other topics to be considered, which will be relevant for the future of higher education institutions. Particularly important are those relating to innovative cross-sectoral investment. If we consider that quality higher education is both a result as well as a catalyst of economic growth and social progress, then it should be presented as a clear example of sustainable financing. Higher education must become more visible, but its financing must become more transparent as well. Accountability is a theme of general interest and some concern in several countries, not only in Latin America but also in other regions. Universities must be set up to deliver their message with trust and credibility, and I believe that therein lies another challenge.

I will end by mentioning a practical example where universities and university associations are much needed these days: data provision. Universities are usually very good at both data generation and rigorous documentation of facts. This can help overcome many global challenges we face, as a number of decisions made at critical policy levels are unfortunately based on misinformation, as surprising as it sounds. Universities dedicate a lot of effort, resources and time to collecting reliable data, to analysing it and systematising it. As a result, they hold information that no other 
set of institutions or organisations in the world has or can generate. We all must take advantage of this and foster active participation and a true contribution from universities and other higher education institutions to the development of solutions to contemporary problems.

Juan Ramón de la Fuente has been the Permanent Representative of Mexico to the United Nations since February 2019. He has served as Mexico's Minister of Health and as Rector of the National Autonomous University of Mexico (UNAM), also as an Emeritus Professor. Juan Ramón de la Fuente has also worked with UNESCO as a member of the Board for Latin America and the Caribbean on Higher Education, and is a former President of the International Association of Universities (2008-2012).

Open Access This chapter is licensed under the terms of the Creative Commons Attribution 4.0 International License (http://creativecommons.org/licenses/by/4.0/), which permits use, sharing, adaptation, distribution and reproduction in any medium or format, as long as you give appropriate credit to the original author(s) and the source, provide a link to the Creative Commons license and indicate if changes were made.

The images or other third party material in this chapter are included in the chapter's Creative Commons license, unless indicated otherwise in a credit line to the material. If material is not included in the chapter's Creative Commons license and your intended use is not permitted by statutory regulation or exceeds the permitted use, you will need to obtain permission directly from the copyright holder.

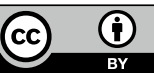

